\title{
Biochemical and physiological responses of sugarcane cultivars to soil water deficiencies
}

\author{
Rafaela Josemara Barbosa Queiroz ${ }^{1}$, Durvalina Maria Mathias dos Santos ${ }^{1}$, Antonio Sergio \\ Ferraudo $^{2}$, Samira Domingues Carlin ${ }^{3 *}$, Marcelo de Almeida Silva ${ }^{4}$ \\ ${ }^{1} U N E S P / F C A V$ - Depto. de Biologia Aplicada à Agropecuária - $14884-900$ - Jaboticabal, SP - Brasil. \\ ${ }^{2} U N E S P / F C A V$ - Depto. de Ciências Exatas - 14884-900 - Jaboticabal, SP - Brasil. \\ ${ }^{3}$ APTA - Polo Centro Oeste, C.P. 66 - 17201-970 - Jaú, SP - Brasil. \\ ${ }^{4}$ UNESP/FCA - Depto. de Produção Vegetal - Agricultura - 18610-970 - Botucatu, SP - Brasil. \\ *Corresponding Author <sdcarlin@apta.sp.gov.br> \\ Edited by: Edmilson José Ambrosano
}

\begin{abstract}
For sugarcane (Saccharum spp.) crops, the effects of an environmental stress, especially water deficiency, may cause severe productivity reduction, inferring negatively in the sugarcane industry. The tolerance of two sugarcane cultivars to a lack of water was made by analyzing the levels of the osmoprotectors, trehalose and free proline, and the biometrical variables of their initial growth. Biochemical and physiological responses of the cultivars, when subjected to water stress, were assayed to determine how these plants tolerate drought. The study was conducted in an acclimatized greenhouse $\left(29.7 \pm 4.3^{\circ} \mathrm{C}\right.$ and $75.0 \pm 10.1 \%$ relative humidity) during 100 days and was divided into random blocks using a factorial $2 \times 3 \times 2$ design (sugarcane cultivars $\times$ water availability $\times$ time periods) with four replicates. Forty days after germination, sugarcane was planted in pots $\left(12 \mathrm{dm}^{3}\right)$ containing topsoil material taken from a medium textured Rhodic Ferralsol, submitted to three levels of water availability (WAS): $55 \%$ (control), $40 \%$ (moderate stress) and 25\% (severe stress), for 60 days. The effect of the WAS on the accumulation of trehalose and free proline was detected in both cultivars, although it was found to be more distinctive for the cv. IAC91-5155. Trehalose and free proline are biochemical and physiological indicators of water deficiency. The cv. IAC91-5155 had altered growth and allocation of biomass when subjected to severe water stress conditions. The univariate and the multivariate analysis of the biochemical and physiological responses, presented by the IAC91-5155 cultivar, indicate relative tolerance to drought conditions.

Key words: Saccharum spp., drought, trehalose, proline, initial growth
\end{abstract}

\section{Introduction}

Sugarcane (Saccharum spp.) is an important industrial crop in Brazil and has been especially cultivated for the production of sugar and biofuel. In the last few years, sugarcane productivity has noticeably suffered from many abiotic types of stress, including water deficiency in the soil which causes irreparable loss to the industry (Maule et al., 2001).

The demand for sugarcane cultivars that present high levels of tolerance to long and severe periods of drought has instigated the interest of the scientific community to investigate biochemical and physiological mechanisms used by these plants to respond to different types of stress (Ashraf and Foolad, 2007). Osmotic adjustment is an important mechanism of tolerance to lack of water where osmoprotectors are accumulated in plant vacuoles or in the cytosol to maintain the water balance and preserve cellular integrity of protein, enzymes and cell membranes (Jaleel et al., 2007). Many substances act as osmoprotectors: the disaccharide, trehalose, and the amino acid, proline, are the most prominent and the accumulation of these compounds in plant tissues is described as a method to establish osmoprotection in cultivars that are found to be resistant to drought conditions (Bartels and Sunkar, 2005; Paul et al., 2008).

The study of physiological tools that facilitate the development of sugarcane cultivars more adapted to distinct management conditions and to specific areas of cultivation is of utmost importance to maintain yield and productivity levels
(Queiroz et al., 2008; Silva et al., 2008; Queiroz and Santos, 2009; Carlin and Santos, 2009).

A multivariate analysis is an exploratory method that characterizes the interaction of data in the comprehension of the mutual influence of biochemical and physiological responses in plants to adverse conditions. This study would differ from a univariate study who analyzes phenomena separately (Fukusaki and Kobayashi, 2005). The present study aimed to verify- for two contrasting sugarcane cultivars- their tolerance levels to drought conditions in addition to the response of their biochemical and physiologic indicators to water stress by assessing the levels of osmoprotectors, trehalose and free proline, and the biometric variables of their initial growth.

\section{Materials and Methods}

The study was conducted in a greenhouse (internal temperature of $29.7 \pm 4.3^{\circ} \mathrm{C}$, and relative air humidity of 75.0 $\pm 10.1 \%$ ) located in Jaboticabal, state of São Paulo, Brazil, from October to December, 2005. Random blocks in a $2 \times$ $3 \times 2$ factorial design were used, which were composed of two cultivars; three levels of water availability in the soil (WAS): control (WAS1), moderate stress (WAS2) and severe stress (WAS3), with, respectively, 55\%, 40\% and $25 \%$ of their pores filled with water; and two time periods of water stress $(\mathrm{P}), 30$ days $(\mathrm{P} 1)$ and 60 days $(\mathrm{P} 2)$, which encompassed the initial stages of growth: 70 days (P1) and 100 days (P2) with four replicates. 
To verify the effect of water deficiency in the soil, young sugarcane plants of IAC91-2195 (C1) and IAC91-5155 (C2) cultivars were used. These cultivars contrast in their tolerance levels to water deprivation: IAC91-2195 is sensitive while IAC91-5155 is tolerant to drought conditions (Queiroz et al., 2008; Queiroz and Santos, 2009; Carlin and Santos, 2009). Mini cane sets from a bud, nine months of age, were collected from a $3^{\text {rd }}$ cut sugarcane crop (ratoon) cultivated at in

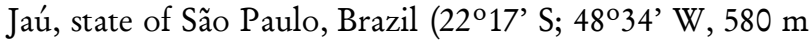
a.s.1.). Twenty-four hours after collection, the cane sets were planted in pots of $0.20 \mathrm{dm}^{3}$ capacity containing topsoil samples $(0-20 \mathrm{~cm})$ taken from a medium textured Rhodic Ferralsol (FAO, 2006). Chemical and particle size analysis presented the following results: $\mathrm{pH} 0.01 \mathrm{M} \mathrm{CaCl}_{2}: 4.9$; organic matter: $13 \mathrm{~g} \mathrm{dm}^{-3}$; $\mathrm{P}$ (resin method) : $5 \mathrm{mg} \mathrm{dm}^{-3}$; K: 2.6 mmol dm${ }^{-3}$; Ca: $20 \mathrm{mmol} \mathrm{dm}^{-3} ; \mathrm{Mg}: 10 \mathrm{mmol} \mathrm{dm}^{-3}$; $\mathrm{H}+\mathrm{Al}: 31 \mathrm{mmol}_{\mathrm{c}} \mathrm{dm}^{-3}$; Al: $1 \mathrm{mmol} \mathrm{dm}^{-3}$; sum of basis: $32.6 \mathrm{mmol} \mathrm{dm}_{\mathrm{c}}^{-3}$; CEC: $63.6 \mathrm{mmol}_{\mathrm{c}} \mathrm{dm}^{-3}$; base saturation: $51 \%$; sand: $650 \mathrm{~g} \mathrm{~kg}^{-1}$, silt: $50 \mathrm{~g} \mathrm{~kg}^{-1}$; clay: $300 \mathrm{~g} \mathrm{~kg}^{-1}$; particle density of $2.73 \mathrm{~g} \mathrm{~cm}^{-3}$. Plants were maintained for $40 \mathrm{~d}$ without restriction of water until being transferred to $12 \mathrm{dm}^{3}$ pots containing the same substrate. After being transplanted, plants were cultivated under the levels of water availability (WAS) mentioned before during $60 \mathrm{~d}$. The WAS volumes, in the $12 \mathrm{dm}^{3}$ pots, corresponded to the following levels of water: $3.07 \mathrm{dm}^{3}, 2.22 \mathrm{dm}^{3}$, and $1.36 \mathrm{dm}^{3}$ for $55 \%, 40 \%$ and $25 \%$ of WAS, respectively. The water levels in the soil were monitored by weight comparisons with the mass of the pots being assessed daily by a digital scale that had a $25 \mathrm{~kg}$ maximum capacity and $\mathrm{a} \pm 0.005 \mathrm{~kg}$ precision. Water supplementation was done daily to maintain the soil water content according to each treatment.

Sugarcane growth rate was verified at the $30^{\text {th }}$ and $60^{\text {th }}$ days after the plants were subjected to water stress; this was made by assessing the leaf lengthening rate (RLL), the dry mass of blade leaf (DML), the dry mass of the stalk + sheath (DMS), the root density (RDS), the mean root diameter (MDR) and the dry mass of roots (DMR). In order to determine the RDS and MDR, the imaging analyzing system Delta-T SCAN was used as recommended by Bidoia et al. (2006). During the last ten days before harvesting (P2), the length of a young expanding leaf (with its ligule not yet evident) was measured daily (always at the same time of the day) from the entire experimental plot to calculate the rate of leaf lengthening. The daily lengthening rate was found by the difference between the measurement of the current day and that taken on the previous day. The rate of leaf lengthening was obtained by the mean value of the measurements.

Determination of trehalose and free proline levels was made on the blade $($ leaf +1$)$ : the first completely expanded leaf from the apical "derwlap" or visible auricle (Dillewijn, 1952) which is ideal for assessing biochemical compounds. To determine the levels of trehalose, $1 \mathrm{~g}$ of fresh leaf tissue was assessed by the enzymatic method described by Neves et al. (1994) and adapted by Queiroz and Santos (2009). The hydrolysis reaction was incubated in a water bath for $1 \mathrm{~h}$ at $60^{\circ} \mathrm{C}$. Each mol of glucose represented $0.5 \mathrm{~mol}$ of treha- lose. Quantification of free proline was determined using 0.5 $\mathrm{g}$ of fresh leaf tissue assessed by the method developed by Bates et al. (1973).

To study individual features, analysis was performed using the $\mathrm{F}$ test with Tukey test applied to compare mean values of the quantitative factors ( $\mathrm{C}$ and $\mathrm{P})$. The analysis of the polynomial regression was used to unfold the degrees of freedom of the quantitative factor, WAS (Banzatto and Kronka, 2006). When analyzing all the data together, a study of the main components was used. This analysis is a transformation that is applied to the amassed data in an attempt to reduce the number of correlated variables - named main components - to retain as much of the original information as possible. These orthogonal components are linear combinations of the original variables (Manly, 1994).

\section{Results and Discussion}

Levels of trehalose were enhanced by the reduction of WAS in the two sugarcane cultivars (Table 1; Figure 1A). This was observed after the $60^{\text {th }}$ stressed day and this increase was found to be $12 \%$ higher for cultivar IAC91-5155 when compared to IAC91-2195 (Figure 1). Carlin and Santos (2009) evaluated the sugarcane variety IAC91-5155 under water stress and observed a trehalose accumulation of $25.9 \%$ (increase of $0.54 \mu \mathrm{mol} \mathrm{g}^{-1}$ fresh mass weight) at the $60^{\text {th }}$ day under stress, reaching concentrations of trehalose of 2.54 $\mu \mathrm{mol} \mathrm{g}{ }^{-1}$ of the fresh weight. There is a distinction among cultivars regarding the ability of trehalose biosynthesis, regardless of the level of soil moisture and period under stress (Queiroz and Santos, 2009). This difference may be an evidence of tolerance to adverse conditions among different botanical materials. The osmoprotectant effect of the trehalose is highlighted, which is an important trait of acclimatization, which promotes benefits to plants under water restriction (Garg et al., 2002). Among the disaccharides, trehalose has specific properties by replacing the water removed under conditions of dehydration, allowing the hydrophilic structures to remain hydrated (Crowe, 2007). In fact, there is no passage of the fluid phase to the gel phase of the membrane with the replacement of water molecules by trehalose, maintaining the integrity and fluidity, and thus, the cell viability (Wingler, 2002; Patist and Zoerb, 2005).

This enhancement is caused by an increase in non-structural carbohydrates. Therefore, it is supposed that the increase in trehalose in the leaf limbus under conditions of low water availability in the soil could be related to modifications in the metabolism of carbohydrates (Bartels and Sunkar, 2005). These polymers, which are mostly compartmentalized, would suffer a decrease in their levels because of their role in preserving plasmatic membranes, which would be unstable because of the dry conditions. Therefore, the demand for these carbohydrates would also be increased (Patist and Zoerb, 2005; Paul et al., 2008). However, trehalose accumulation in superior vascular plants under adverse conditions is not common, which suggests that, in order to preserve these structures in most species, sucrose would be more active than trehalose. In superior plants, the concentrations of 
Table 1 - Factorial analysis of variance: data referring to biochemical-physiological responses of young plant blade leaves (leaf +1$)$ of sugarcane cultivars subjected to different water availabilities in the soil during 30 or 60 days. Data ( $F$-test): leaf lengthening rate (RLL), the dry mass of blade leaf (DML), the dry mass of the stalk + sheath (DMS), the dry mass of roots (DMR), the root density (RDS), the mean root diameter (MDR), trehalose content (TRE) and free proline content (PRO).

\begin{tabular}{|c|c|c|c|c|c|c|c|c|c|}
\hline \multirow{2}{*}{ Source } & \multirow{2}{*}{ D.F. } & \multicolumn{8}{|c|}{$p$ value of biochemical-physiological responses } \\
\hline & & RLL & $\mathrm{DML}$ & DMS & DMR & RDS & MDR & TRE & PRO \\
\hline Cultivars (C) & 1 & $0.01 \% *$ & $0.01 * *$ & $0.56^{\mathrm{ns}}$ & $0.01 * *$ & $0.01 * *$ & $0.01 * *$ & $0.01 * * *$ & $0.01 * *$ \\
\hline Water Availability in the Soil (WAS) & 2 & $0.01 \% *$ & $0.01 \% *$ & $0.01^{* * *}$ & $0.01 \% *$ & $0.17^{\mathrm{ns}}$ & $0.01 * * *$ & $0.01 * *$ & $0.01 \% *$ \\
\hline Periods $(\mathrm{P})$ & 1 & $0.01 \%$ & $0.01 * *$ & $0.01 * *$ & $0.01 \% *$ & $0.01^{\mathrm{ns}}$ & $0.15^{\mathrm{ns}}$ & $0.01 * \%$ & $0.01 * *$ \\
\hline Interaction $\mathrm{C} \times$ WAS & 2 & $0.06^{\mathrm{ns}}$ & $0.61^{\mathrm{ns}}$ & $0.01 \% *$ & $0.80^{\mathrm{ns}}$ & $0.40^{\text {ns }}$ & $0.33^{\mathrm{ns}}$ & $0.01 \% *$ & $0.15^{\mathrm{ns}}$ \\
\hline Interaction $\mathrm{C} \times \mathrm{P}$ & 1 & $0.26^{\mathrm{ns}}$ & $0.09^{\mathrm{ns}}$ & $0.73^{\mathrm{ns}}$ & $0.01 * * *$ & $0.12^{\mathrm{ns}}$ & $0.08^{\mathrm{ns}}$ & $0.95^{\mathrm{ns}}$ & $0.64^{\mathrm{ns}}$ \\
\hline Interaction WAS $\times \mathrm{P}$ & 2 & $0.01 \% *$ & $0.02 \%$ & $0.01^{* * *}$ & $0.01 \% \%$ & $0.50^{\mathrm{ns}}$ & $0.17^{\mathrm{ns}}$ & $0.04 \%$ & $0.87^{\mathrm{ns}}$ \\
\hline Interaction $\mathrm{C} \times$ WAS $\times \mathrm{P}$ & 2 & $0.11^{\mathrm{ns}}$ & $0.94^{\mathrm{ns}}$ & $0.01 * *$ & $0.69^{\mathrm{ns}}$ & $0.67^{\mathrm{ns}}$ & $0.23^{\mathrm{ns}}$ & $0.02 *$ & $0.07^{\mathrm{ns}}$ \\
\hline Treatments & 11 & - & - & - & - & - & - & - & \\
\hline Block & & $0.81^{\mathrm{ns}}$ & $0.96^{\mathrm{ns}}$ & $0.84^{\mathrm{ns}}$ & $0.61^{\mathrm{ns}}$ & $0.91^{\mathrm{ns}}$ & $0.88^{\mathrm{ns}}$ & $0.80^{\mathrm{ns}}$ & $0.77^{\mathrm{ns}}$ \\
\hline Error & 36 & - & - & - & - & - & - & - & \\
\hline Total & 47 & - & - & - & - & - & - & - & \\
\hline Coefficient of variance & - & 12.23 & 16.26 & 16.85 & 18.60 & 26.83 & 28.62 & 18.20 & 05.69 \\
\hline
\end{tabular}

$F$-test: **significative $(p \leq 0.01)$; *significative $(p \leq 0.05)$; ${ }^{\text {nn }}$ not-significative $(p>0.05)$. The data are means of four replicates.
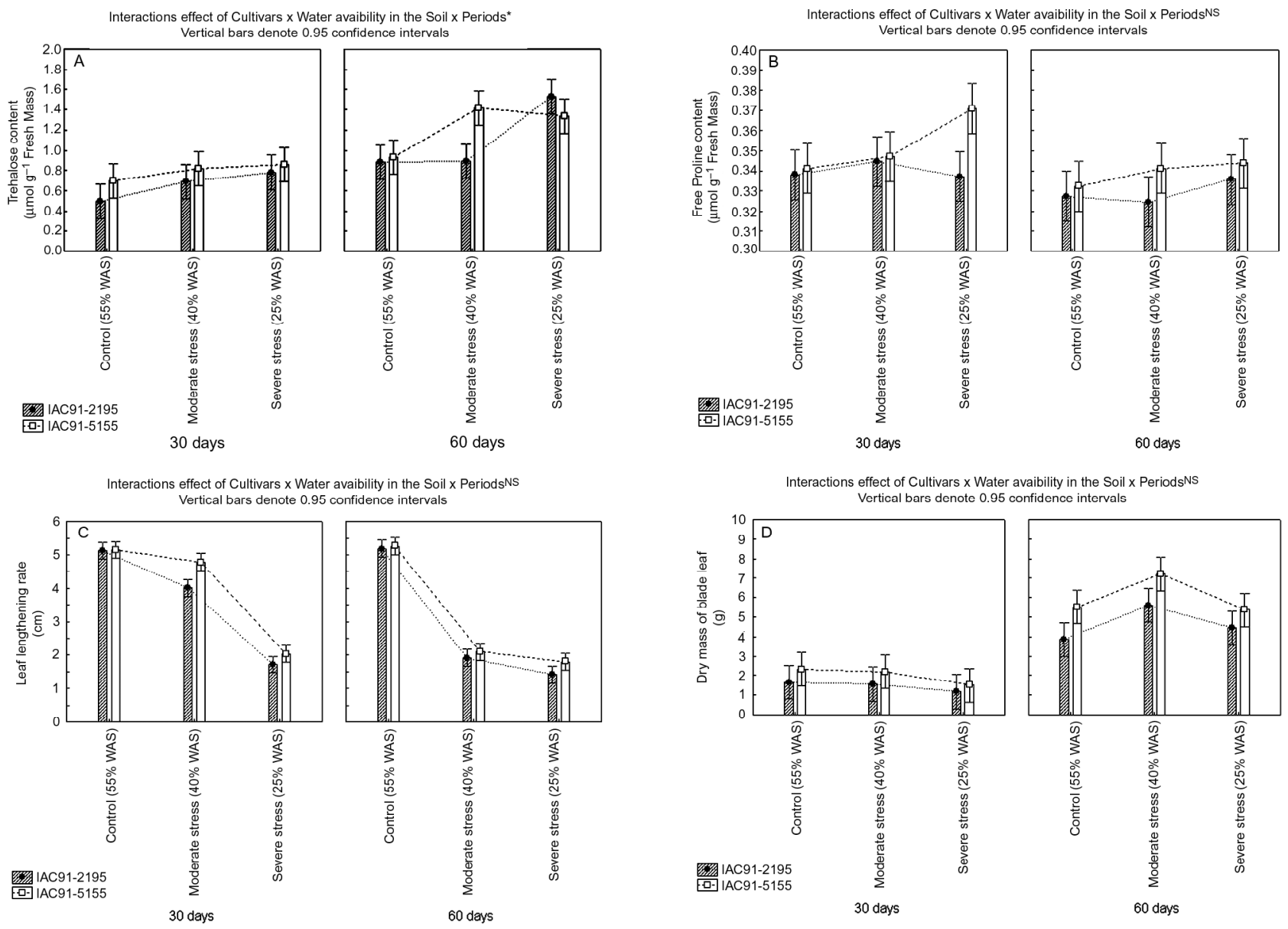

Figure 1 - Data referring to biochemical-physiological responses of young plants of sugarcane cultivars, IAC91-2195 and IAC91-5155, subjected to water availabilities in the soil during 30 or 60 days. The means of each factor: cultivar, water availability in the soil and periods, as well the factories interactions denote 0.95 confidence intervals. (A) trehalose content, (B) free proline content in blade leaves (leaf +1 ), (C) leaf lengthening rate; (D) dry mass of blade leaf of sugarcane plants. The data are means of four replicates \pm SD. 
sucrose are higher than those of trehalose because the cellular action of trehalose occurs in low levels to prevent the damaging effect that its accumulation can have on the carbon metabolism regulation (Wingler, 2002; Almeida et al., 2007).

Other disaccharides, such as sucrose and maltose when compared to trehalose, partially induce cellular stability and that the effect of this carbohydrate in stabilizing membranes under conditions of water deficiency can be three times more efficient than sucrose due to the molecule's strong affinity to hydrogen bridge type links (Patist and Zoerb, 2005). Since the metabolism of trehalose was only recently discovered in superior plants, there is little information that validates its real function in plant physiology and development (ElBashiti et al., 2005).

An increase in the amassment of free proline was noted when there was a decrease in WAS only in C2 after $30 \mathrm{~d}$ (Table 1; Figure 1B). This amino acid accumulation indicates this cultivar's tolerance to water stress conditions: in other Poaceae (Fumis and Pedras, 2002; Hongbo et al., 2006), and even in sugarcane (Ríncones, 1997; Bidoia et al., 2006), there is an inverse correlation between the amounts of free proline and the variation in the levels of water stress. In these aforementioned studies, the highest amounts of proline have been found in plants who were subjected to lower WAS conditions, although the amounts accumulated in the others species or genotypes studied by these researchers were different (Ríncones, 1997; Fumis and Pedras, 2002; Bidoia et al., 2006; Hongbo et al., 2006), were superior to those observed in the present study. However, this study was carried out in accordance to the ideal accumulation contents stipulated by Bates et al. (1973) for studies of water stress in plants. Carlin and Santos (2009) observed an increase of 13.6\% $(=0.08$ $\mu \mathrm{mol} \mathrm{g}{ }^{-1}$ fresh weight) in the proline content in the same sugarcane variety with increased intensity of drought in the initial plant growth period. This increment could be linked to the increase in the biosynthesis of proline related to tissue water potential. This is a mechanism of protection against a water deficit since proline would help lower the water potential by retaining water in situ and maintaining the integrity of these tissues (Kishor et al., 2005).

Part of the studies who pertain to plants under conditions of water deficiency give evidence to the fact that the accumulation of this amino acid increases gradually according to the imposed stress period (Yamada et al., 2005), although in some wheat cultivars, this osmolyte showed a tendency to stabilize and/or decrease (Fumis and Pedras, 2002). The consistency of the amounts found during the collection of samples from some of the cultivars could be attributed to the acclimatization of the plant to stress characterizing a degree of tolerance (Bidoia et al., 2006; Queiroz and Santos, 2009). This could explain the fact that the WAS did not have a significant effect on C2P2. Besides the advantages that free proline provides the maintenance of cellular turgescence, it would also be an immediate accessible source of energy for tissue growth and development (Kishor et al., 2005). For this to occur, proline would be translocated throughout the phloem tissue to the root system to maintain turgidity of these cells and would also act as an energy source for growth and development in the root tissue. Raymond and Smirnoff (2002) observed an increase of free proline in the phloem of seedlings under water stress with expressive levels also in the root apical meristem when compared to other areas of the root system and to the aerial part of the plants. Considering this point of view, it would be important to know how the accumulation of free proline would exert influence on other pathways related to the production of energy and to the metabolism of carbon during water stress (Kishor et al., 2005). Therefore, this osmotic adjustment could also help maintain leaf cell elongation and expansion of growth areas under conditions of water deficiency (Ashraf and Foolad, 2007; Jaleel et al., 2007).

Intensification of this stress reduced the RLL of the sugarcane cultivars assessed in this study after $60 \mathrm{~d}$ (Table 1; Figure 1C). Thus a decrease in RLL could be explained by the reduction in cell elongation due to a decrease in turgidity (Taiz and Zeiger, 2009). The RLL levels depend on the pressure exerted by turgidity, which is extremely sensible to drought. The continuance of leaf elongation, even when this is reduced under conditions of severe water stress, could also be linked to the accumulations of trehalose and free proline in the leaf tissue of the assessed sugarcane cultivars. This variable could be useful as a tool for an early evaluation of the cultivars for conditions of water deficiency (Dias-Filho, 2011). The accumulation of these osmotic protectors occurs to diminish the osmotic potential and subsequently keeps water potential and cell turgidity close to optimal levels with the expansion of leaf tissue being partially maintained (Serraj and Sinclair, 2002).

WAS values lower than $42 \%$ and $42.3 \%$ caused a decrease in DML (Table 1, Figure 1D) and MDR (Table 1, Figure 2D), respectively, after $60 \mathrm{~d}$. The DMS had the highest levels (16.63 g) when $43.4 \%$ of the pores were filled with water (Figure 2A). Considering DMR in IAC 91-5155 there was an increase of these levels after 60 days when compared to the IAC912195 (Figure 2B). This last cultivar presented a DMR 44\% lower $(6.36 \mathrm{~g})$ than that of the tolerant cultivar $(11.37 \mathrm{~g})$.

In general, grasses subjected to water stress conditions tend to decrease the allocation of dry mass to their leaves proportionally to the reduction of water availability in the soil giving priority to root growth (Ramesh, 2000; Dias-Filho, 2011). This tendency was verified in the present study after the moment of maximum accumulation of DML had been attained with almost $40 \%$ of the pores filled with water (Table 1, Figure 1D). This would be due to the tendency of the plant aerial portion to grow until the absorption of water by the roots becomes limiting, which means that this increase of DMR could be attributed to the decrease in DML that occurs under conditions under which $25 \%$ of the pores were filled with water. In this situation, the use of carbon and energy is diminished favoring an increase in the distribution of photo-assimilated substances to the root system to sustain organ growth (Taiz and Zeiger, 2009).

Bidoia et al. (2006) evaluated sugarcane plants in different growth phases being subjected to drought and observed a higher reduction in the accumulation of dry mass in the vegetative stage with their growth reduced to 61 and $46 \%$ 

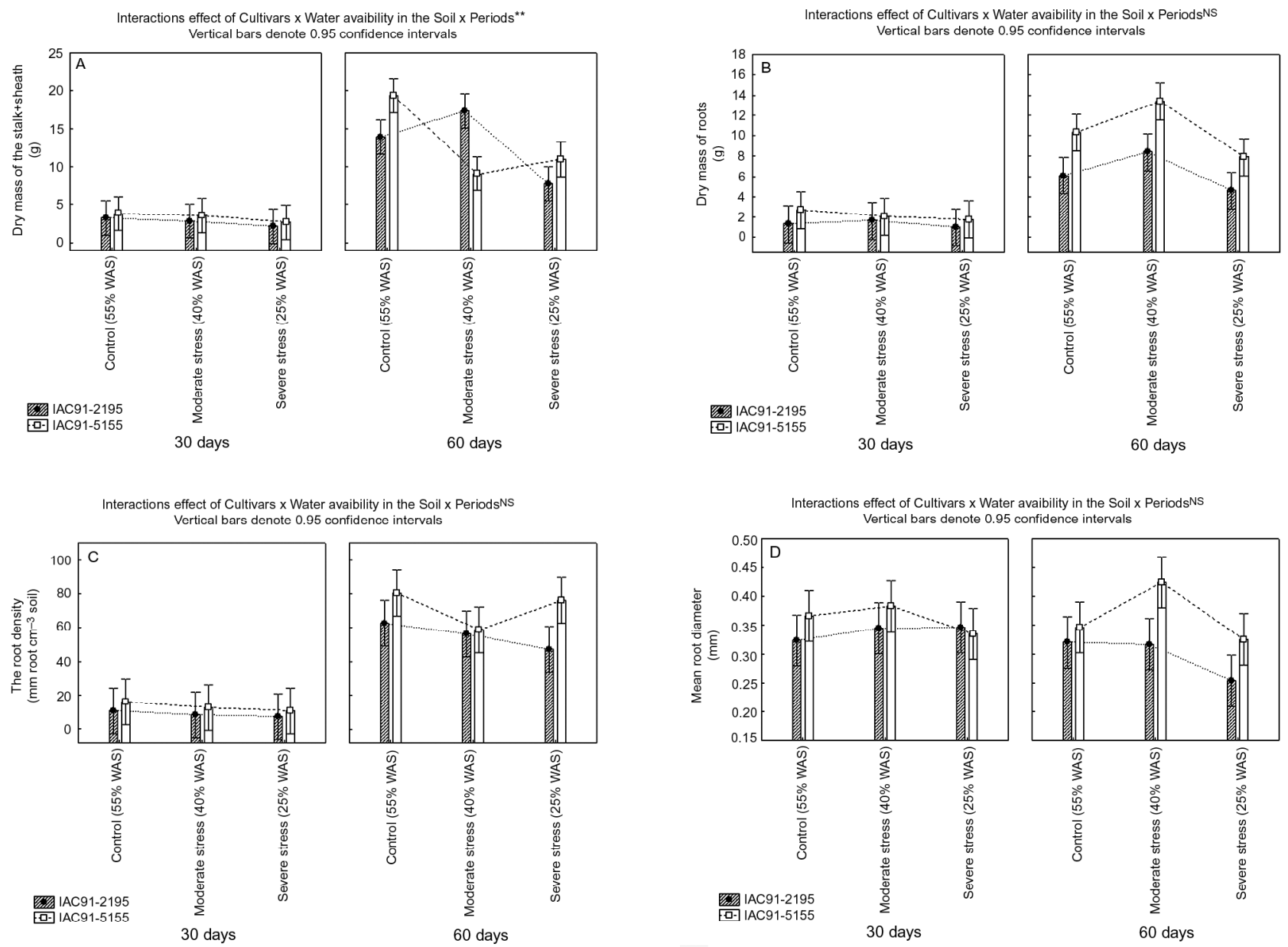

Figure 2 - Data referring to biochemical-physiological responses of young plants of sugarcane cultivars, IAC91-2195 and IAC91-5155, subjected to water availabilities in the soil during 30 or 60 days. The means of each factor: cultivar, water availability in the soil and periods, as well the factories interactions denote 0.95 confidence intervals. (A) dry mass of the stalk + sheath; (B) dry mass of roots, $(C)$ root density and (D) mean root diameter of sugarcane plants. The data are means of four replicates \pm SD.

when submitted to conditions of moderate and severe water stress, respectively. Moreover, Ramesh (2000) found differential response of five sugarcane genotypes for the number of leaves and the division of dry mass when they were subjected to dry conditions in comparison with irrigated conditions during the vegetative growth phase. These results were similar to those found in the present study. However, the response regarding the physiological modifications in the aerial portion and the root system of sugarcane plants, under conditions of water stress, is influenced by the genotypes of the cultivars due to the vegetative state in which the plant is found, by the severity and the periodicity of the lack of water (Ramesh, 2000; Vasconcelos et al., 2003; Silva et al., 2008), and by the type of soil regarding its porosity (Camilotti et al., 2005).

For the sugarcane plants under conditions of low water potential, the highest accumulation of DMS at the more severe WAS is peculiar since the stalk is an organ used as a drain. The competition between these drains determines the pattern for transportation of photo-assimilated products (Taiz and Zeiger, 2009) due to a tendency to allocate dry mass drained from the leaves to the stalks rather than to the root system. Besides this fact, the product of major economic in- terest in this crop is the amount of sucrose accumulated in stalks. Under water stress, a competition of these organs for the photo-assimilated products occurs, which could reflect on the effect of WAS on the DMR and the RDS (Root density system), but it was not significant (Table 1, Figure 2C). These results go against those found in the literature since in a study on sugarcane under water stress, the dry mass of the roots and the density of these roots decreased when the water available in the soil decreased for 120 days (Bidoia et al., 2006).

Each cultivar has a different inherent root system which, in some situations, can compete for the photo-assimilated products and which can have a negative effect on productivity (Vasconcelos et al., 2003; Faroni and Trivelin, 2006). Furthermore, as the studied cultivars have different levels of tolerance to adverse conditions and consequently, present different levels of productivity, cultivar IAC91-5155 has the best performance and is considered the most productive and the more resistant of the sugarcane cultivars (Silva et al., 2006).

The root distribution of a cultivar can determine, in most part, its adaptation to the environment regarding climatic conditions and type of soil (Vasconcelos et al., 2003). Severe 
water stress $(25 \%)$ promoted growth of fine roots indicating a smaller MDR (Table 1; Figure 2D). Therefore, plants surviving under conditions of drought would tend to increase the production of absorbing hairs (thinner roots) to optimize water absorption (Aiken and Smucker, 1996; Faroni and Trivelin, 2006).

The growth of thin roots toward moist soil regions was observed for plants under conditions of 25\% WAS (more severe stress). For such roots, their contact area with the soil solution and the efficiency of water absorption are larger, probably to establish a mechanism of tolerance to these adverse conditions. Similar results were found by Bidoia et al. (2006) in sugarcane cultivars during phases of initial growth (up to $120 \mathrm{~d}$ ) under conditions of water deficiency, because a quadratic variation of the effect of WAS on MDR was detected in nearly all the growth phases, except at $30 \mathrm{~d}$. Bidoia et al. (2006) also reported that maximum values of MDR were always found between 36 and $34 \%$, which would be a moderate level of stress suggesting that higher levels than these would influence MDR in the same way as the lowest levels of water content in the soil (20\%).

The best performance obtained by sugarcane plants under moderate levels of water stress, in the present study as well as in the study by Bidoia et al. (2006), could be related to the changes in soil density due to modifications of its structure when responding to daily replacement of water. This could have had a negative effect on fundamental physical and water properties such as porosity. The total porosity of the soil would be extremely sensitive to the suffered pressure (Camilotti et al., 2005).

In many Poaceae, the combination of mechanisms used by the plant to delay dehydration (growth of the root system, decrease in mean root diameter) and tolerance to drought (amassing and translocation of assimilated products and osmotic adjustment) are determinant for the capacity of survival of the species during drought (Bartels and Sunkar, 2005). A multivariate analysis of the main components of the physiological evaluations allowed a better assessment of the results (Table 2).
Analyzing the bi-dimensional figure, the first Principal Component Analysis (PCA1) discriminates against the treatments as to the time period. Regarding the PCA1, the treatments regarding $\mathrm{P} 1$ ( 30 days) tend to the right while the treatments regarding P2 $(60 \mathrm{~d})$ tend to the left (Figure $3)$. This axis is responsible for retaining $59.33 \%$ of the original information. The variables DML $(r=-0.96)$, RDS $(r=-0.99)$, DMS $(r=-0.96)$, DMR $(r=-0.96)$, and trehalose $(r=-0.45)$ are responsible for, in this order, the discrimination of $\mathrm{P} 2$, while the variables RLL $(r=0.90)$ and free proline $(r=0.53)$ are responsible for the discrimination of P1. The second Principal Component Analysis (PCA2) was able to discriminate the cultivars $\mathrm{C} 1$ and $\mathrm{C} 2$. The treatments referent to the variety $\mathrm{C} 2$ showed a tendency to be lower when considering PCA2 while the treatments regarding the variety $\mathrm{C} 1$ tended to be located above (Figure 3). This axis is responsible for retaining $18.6 \%$ of the original information. The variables MDR $(r=0.75)$, proline $(r$ $=-0.66)$ and trehalose $(r=-0.69)$ are those responsible, in this order, for the discrimination of C2 of the C1 (Table 2). When analyzing the collected data, $\mathrm{C} 2$ once more pre-

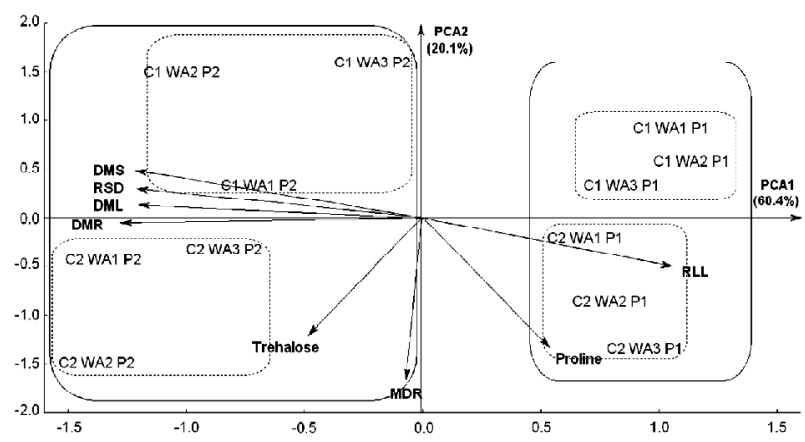

Figure 3 - Biplot of Principal component analysis (PCA) of two sugarcane genotypes under distinct development phase and subjected to different water availabilities in the soil material used as a substratum. Traits belong to developmental and biochemical-physiological responses.

Table 2 - Principal component analysis (PCA) of two sugarcane genotypes subjected to different water availabilities in a soil sample under distinct development phases. Traits belong to developmental and biochemical-physiological responses.

\begin{tabular}{lcc}
\hline & \multicolumn{2}{c}{ Principal component analysis } \\
\cline { 2 - 3 } Variables & PCA1 & PCA2 \\
\cline { 2 - 3 } & & Correlations \\
\hline Leaf lengthening rate (RLL) & 0.90 & -0.28 \\
Dry mass in the blade leaf (DML) & -0.96 & 0.05 \\
Dry mass of stalk + sheath (DMS) & -0.96 & 0.11 \\
Dry mass in the roots (DMR) & -0.96 & -0.14 \\
Root density system (RDS) & -0.99 & 0.04 \\
Mean diameter of the roots (MDR) & -0.03 & -0.77 \\
Proline & 0.51 & -0.66 \\
Trehalose & -0.45 & -0.61 \\
Accumulated percentage & 60.41 & 20.14 \\
\hline
\end{tabular}

Principal component analysis 1 (PCA1); Principal component analysis 2 (PCA2). 
sented the best response, conferring to this variety the best performance under conditions of water stress. This type of assessment could differentiate, qualitatively, the performance of sugarcane cultivars, and with the results, classify them as being sensitive (C1) and tolerant (C2) to water stress. Together, the two components could retain $78 \%$ $(59.33+18.64)$ of the variability of the original combination (Table 2).

Dias-Filho (2011) and Marin et al. (2006) also detected a tendency for different degrees of tolerance to sub-optimal environmental conditions in their assessment of physiological responses together in plants under conditions of stress. Therefore, quantitative and qualitative measurements of large responses of metabolites and growth of plants thus provide a broad view of the acclimated status of sugarcane plants that can be used to monitor and assess abiotic responses. Principal component analysis is one of the oldest and most widely used multivariate techniques. Plotting the data in the space defined by the two or three largest PCAs provides a rapid means of visualizing similarities or differences in the data set, perhaps allowing for improved discrimination of samples. (Sumner et al., 2003)

The increase in levels of trehalose and free proline found in the present study confirms what many others have reported: the importance of the osmotic adjustment of plant species, genotypes and cultivars to water deficiency in the soil (Garg et al., 2002; El-Bashiti et al., 2005; Hongbo et al., 2006). These authors declare that this mechanism is related to the accumulation of compatible osmolytes in plant tissue as its response to drought, a mechanism which maintains cell turgidity and facilitates physiological and biochemical processes under these conditions. When this occurs, plants who are more tolerant to drought conditions, usually would present higher levels of trehalose and free proline in their tissue (ElBashiti et al., 2005; Bidoia et al., 2006; Hongbo et al., 2006). However, the affirmation that these osmolytes increase in correlation with the increase of time under which the plant is subjected to water stress should be made with caution since there are many biochemical reactions and physiological modifications that interact.

\section{Conclusions}

For young sugarcane plants of the cv. IAC91-5155, the osmoprotectors trehalose and free proline are indicators of the effects of water stress in the soil. There are modifications in growth and in the allocation of biomass in $\mathrm{cv}$. IAC91-5155 when under conditions of severe water stress. The univariate and the multivariate analysis of the biochemi$\mathrm{cal}$ and physiological response indicate relative tolerance to drought for the cv. IAC91-5155.

\section{Acknowledgements}

To Prof. João A. Jorge (USP/FFCRP) and to Giovanna C. Gianesi for the assistance in the biochemical analysis, to Profs. Jairo O. Cazetta and David A. Banzatto (UNESP/ FCAV) for the offered suggestions; and to CNPq for the scholarship to R.J.B. Queiroz.

\section{References}

Aiken, R.M.; Smucker, A.J.M. 1996. Root system regulation of whole plant growth. Annual Review of Phytopathology 34: 325-346.

Almeida, A.M.; Cardoso, L.A.; Santos, D.M.; Torné, J.M.; Fevereiro, P.S. 2007. Trehalose and its applications in plant biotechnology. In Vitro Cellular and Developmental Biology-Plant 43: 167-177.

Ashraf, M.; Foolad, M.R. 2007. Roles of glycine betaine and proline in improving plant abiotic stress resistance. Environmental and Experimental Botany 59: 206-216.

Banzatto, D.A.; Kronka, S.N. 2006. Agricultural Experimentation. 4ed. Funep, Jaboticabal, SP, Brazil. (in Portuguese).

Bartels, D.; Sunkar, R. 2005. Drought and salt tolerance in plants. Critical Reviews in Plant Sciences 24: 23-58.

Bates, L.S; Waldrew, R.P.; Teare, I.D. 1973. Rapid determination of free proline for water-stress studies. Plant and Soil 39: 205-207.

Bidoia, M.A.P.; Santos, D.M.M.; Marin, A.; Landell, M.G.A.; Banzatto, D.A.; Cazetta, J.O. 2006. Effect of water deficiency on free proline accumulation in sugar cane at different developmental periods. Stab - Açúcar, Álcool e Subprodutos 24: 6-9 (in Portuguese with abstract in English).

Camilotti, F.; Andrioli, I.; Dias, F.L.F.; Casagrande, A.A.; Silva, A.R.; Mutton, M.A.; Centurion, J.F. 2005. Long-term effect of soil tillage systems with and without tillage of green-cane stump in soil physical properties. Engenharia Agrícola 25: 189-198 (in Portuguese with abstract in English).

Carlin, S.D.; Santos, D.M.M. 2009. Physiological indicators of the interaction between water deficit and soil acidity in sugarcane. Pesquisa Agropecuária Brasileira 44: 1106-1113 (in Portuguese with abstract in English).

Crowe, J.H. 2007. Trehalose as a "chemical chaperone": fact and fantasy. Advances in Experimental Medicine and Biology 594: 143-158.

Dias-Filho, M.B. 2011. Degraded pastures: processes, reasons and recovery strategies. 4ed. MBDF, Belém, PA, Brazil (in Portuguese).

Dillewijn, C. van. 1952. Botany of Sugarcane. Chronica Botanica, Walthham, MA, USA.

El-Bashiti, T.; Hamamci, H.; Oktem, H.A; Yucel, M. 2005. Biochemical analysis of trehalose and its metabolizing enzymes in wheat under abiotic stress conditions. Plant Science 169: 47-54.

Faroni, C.E.; Trivelin, P.C.O. 2006. Quantification of sugar cane active metabolism roots. Pesquisa Agropecuária Brasileira 41: 1007-1013 (in Portuguese, with abstract in English).

Food and Agriculture Organization [FAO]. 2006. World Reference Base for Soil Resources 2006: A Framework for International Classification, Correlation and Communication. FAO, Rome, Italy. 145 p. (World Soil Resources Report, 103).

Fukusaki, E; Kobayashi, A. 2005. Plant metabolism: potential for practical operation. Journal of Bioscience and Bioengineering 100: 347-354.

Fumis, T.F.; Pedras, J.F. 2002. Proline, diamine and polyamines accumulation in wheat cultivars submitted to water deficits. Pesquisa Agropecuária Brasileira 37: 449-453 (in Portuguese with abstract in English).

Garg, A.K.; Ranwala, A.; Owens, T.; Miller, W.B.; Wu, R.J. 2002. Endogenous trehalose detection from leaf tissue of rice, maize, wheat, sorghum, sugarcane, pearl millet, arabidopsis and tobacco by HPLC Plant. In: Proceedings of the National Academy of Sciences of United States of America, San Diego, p. 12-16. Available at: http://www.intl-pag.org/10/abstracts/PAGX_P775.html [Accessed Apr. 15, 2004]

Hongbo, S.; Zongsuo, L.; Mingan, S. 2006. Osmotic regulation of 10 wheat (Triticum aestivum L.) genotypes at soil water deficits. Colloids and Surfaces B: Biointerfaces 47: 132-139.

Jaleel, C.A.; Manivannan, P.; Kishorekumar, A.; Sankar, B; Gopi, R.; Somasundaram, R.; Paneerselvam, R. 2007. Alterations in osmoregulations, antioxidant enzymes and indole alkaloid levels in Catharanthus roseus exposed to water deficit. Colloids and Surfaces B: Biointerfaces 59: 150-157. 
Kishor, P.B.K.; Sangam, S.; Amrutha, R.N.; Sri Laxmi, P.; Naidu, K.R.; Rao, S.S.; Rao, S.; Reddy, K.J.; Theriappan, P.; Sreenivasulu, N. 2005. Regulation of proline biosynthesis, degradation, uptake and transport in higher plants: Its implications in plant growth and abiotic stress tolerance. Current Science 88: 424-438.

Manly, B.F.J. Multivariate Statistical Methods. 1994. Chapman \& Hall, London, UK.

Marin, A.; Santos, D.M.M.; Banzatto, D.A.; Codognoto, L.M. 2006. Influence of water availability and soil acidity on the level of free proline in pigeon pea. Pesquisa Agropecuária Brasileira 41: 355358 (in Portuguese with abstract in English).

Maule, R.F.; Mazza, J.A.; Martha Jr., G.B. 2001. Productivity of sugar cane cultivars in different soils and harvesting periods. Scientia Agricola 58: 295-301 (in Portuguese, with abstract in English).

Neves, M.J.; Terenzi, H.F.; Leone, F.A.; Jorge, J.A. 1994. Quantification of trehalose in biological samples with a conidial trehalase from the thermophilic fungus Humicola grisea var. thermoidea. World Journal of Microbiology and Biotechnology 10: 17-19.

Patist, A.; Zoerb, H. 2005. Preservation mechanisms of trehalose in food and biosystems. Colloids and Surfaces B: Biointerfaces 40: 107-113.

Paul, M.J.; Primavesi, L.F.; Jhurreea, D.; Zhang, Y. 2008. Trehalose metabolism and signaling. Annual Review of Plant Biology 59: 417-441.

Queiroz, R.J.B.; Santos, D.M.M. 2009. Determination of trehalose by trehalase conidial in sugar cane under water deficiency. Stab Açúcar, Álcool e Subprodutos 28: 35-37 (in Portuguese, with abstract in English).

Queiroz, R.J.B.; Santos, D.M.M.; Carlin, S.D.; Marin, A.; Banzatto, D.A.; Cazetta, J.O. 2008. Effects of osmoprotectors on sugar cane plants growing under different water deficit levels. Científica 36: 107115 (in Portuguese, with abstract and figures in English).

Ramesh, P. 2000. Effect of different levels of drought during the formative phase on growth parameters and its relationship with dry matter accumulation in sugarcane. Journal of Agronomy and Crop Science 85: 83-89.
Raymond, M.J.; Smirnoff, N. 2002. Proline metabolism and transport in maize seedlings at low water potential. Annals of Botany 89: 813-823.

Ríncones, C. 1997. Variation on proline contents in eight sugar cane varieties at four soil humidity levels. Caña de Azúcar 15: 3-16 (in Spanish with abstract in English).

Serraj, R.; Sinclair, T.R. 2002. Osmolyte accumulation: can it really help increase crop yield under drought conditions? Plant, Cell and Environment 25: 333-341.

Silva, M.A.; Silva, J.A.G.; Enciso, J.; Sharma, V.; Jifon, J. 2008. Yield components as indicators of drought tolerance of sugarcane. Scientia Agricola 65: 620-627.

Silva, M.A.; Carlin, S.D.; Caputo, M.M. 2006. Harvest types and times of glyphosate application in the eradication of sugarcane rations. Pesquisa Agropecuária Brasileira 41: 43-49 (in Portuguese with abstract in English).

Sumner, L.W.; Mendes, P.; Dixon, R.A. 2003. Plant metabolomics: largescale phytochemistry in the functional genomics era. Phytochemistry 62: 817-836.

Taiz, L.; Zeiger, E. 2009. Plant Physiology. 4ed. Artmed, Porto Alegre, RS, Brazil (in Portuguese).

Vasconcelos, A.C.M.; Casagrande, A.A.; Perecin, D.; Jorge, L.A.C.; Landell, M.G.A. 2003. Evaluation of the sugar cane root system with different methods. Revista Brasileira de Ciência do Solo 27: 849858 (in Portuguese with abstract in English).

Wingler, A. 2002. The function of trehalose biosynthesis in plants. Phytochemistry 60: 437-440.

Yamada, M.; Morishita, H.; Urano, K.; Shiozaki, N.; Yamaguchi-shinozaki, K.; Shinozaki, K.; Yoshiba, Y. 2005. Effects of free proline accumulation in petunias under drought stress. Journal of Experimental Botany 56: 1975-1981.

Received September 21, 2009

Accepted April 14, 2011 